Peter J. Strouse

Jack O. Haller

Walter E. Berdon

Mark A. Rosovsky

Richard D. Bellah

Mason Barr Jr.

\section{Horseshoe adrenal gland in association with asplenia: presentation of six new cases and review of the literature}

Received: 11 December 2001

Accepted: 29 March 2002

Published online: 27 July 2002

(C) Springer-Verlag 2002

\section{P.J. Strouse ( $\square)$}

Section of Pediatric Radiology,

C.S. Mott Children's Hospital,

Room F3503, University of Michigan

Medical Center, 1500 East Medical Center

Drive, Ann Arbor, MI 48109-0252, USA

E-mail: pstrouse@umich.edu

Tel.: + 1-734-7632570

Fax: + 1-734-7649351

J.O. Haller

Department of Radiology, Beth Israel Medical Center, New York, NY, USA

W.E. Berdon

Department of Pediatric Radiology,

Columbia-Presbyterian Medical Center,

New York, NY, USA

M.A. Rosovsky

Department of Radiology,

Newark Beth Israel Medical Center,

Newark, New Jersey, USA

R.D. Bellah

Department of Radiology,

The Children's Hospital of Philadelphia, Philadelphia, PA, USA

M. Barr Jr.

Department of Pediatrics,

University of Michigan Medical Center, Ann Arbor, MI, USA

M. Barr Jr.

Department of Pathology,

University of Michigan Medical Center,

Ann Arbor, MI, USA

M. Barr Jr.

Department of Obstetrics and Gynecology, University of Michigan Medical Center,

Ann Arbor, MI, USA
Abstract Background: Asplenia syndrome is a form of heterotaxy characterized by bilateral rightsidedness. Congenital fusion of the adrenal glands ("horseshoe adrenal gland") is a less common feature of asplenia syndrome, most instances of which have been found at autopsy. Purpose: To present clinical and imaging features of infants diagnosed with asplenia syndrome and horseshoe adrenal gland. Materials and methods: Six infants with asplenia syndrome were identified as having a horseshoe adrenal gland. Medical records and imaging studies were reviewed to determine clinical presentation, associated anomalies, and outcome. The literature was reviewed for prior reports of horseshoe adrenal gland. Results:

Horseshoe adrenal gland was identified in five infants by sonography and one by CT, the latter confirmed by autopsy. In all cases, the horseshoe adrenal gland was pre-aortic. Besides features of asplenia syndrome, one infant also had associated vertebral anomalies and bilateral renal agenesis. Including the current cases, of 65 reported cases of horseshoe adrenal gland 34 $(52 \%)$ were associated with asplenia, $24(37 \%)$ with neural tube defects, $19(29 \%)$ with renal anomalies, and 2 (3\%) with Cornelia de Lange syndrome. Horseshoe adrenal gland has not been reported with polysplenia syndrome. Conclusions: Horseshoe adrenal gland is a less common manifestation of asplenia that may be demonstrated by imaging. Horseshoe adrenal gland may be a differentiating feature between asplenia and polysplenia.
Keywords Adrenal gland (anomalies) - Asplenia · Neonate $\cdot$ Ultrasound 


\section{Introduction}

Asplenia syndrome is a form of heterotaxy characterized by bilateral right-sidedness. Apslenia is associated with bilateral trilobed lungs with bilateral epiarterial bronchi, cardiovascular malformation, midline liver, absence of the spleen, and gastrointestional anomalies, including microgastria, mesogastria, and malrotation $[1,2,3,4]$. Manifestations of asplenia syndrome vary from child to child. Horseshoe adrenal gland is a less common feature of asplenia. Most instances of this anomaly were found at autopsy $[1,2,3,4,5,6,7,8,9]$. We report six infants with asplenia in whom horseshoe adrenal gland was diagnosed by imaging in living infants.

\section{Case reports}

Six cases of horseshoe adrenal gland in association with asplenia were identified drawing from five different institutions. In each case, a clinically suspected diagnosis of asplenia was confirmed by cross-sectional imaging (sonography or computed tomography (CT)). Imaging studies and medical records of these patients were reviewed to identify associated anomalies. The literature was reviewed to identify prior reports of horseshoe adrenal gland.

\section{Results}

Horseshoe adrenal glands were identified in five infants by sonography (Fig. 1) and in a sixth by computed tomography (Fig. 2). Four infants diagnosed by sonography were 1-4 days old, and the fifth was 1 month old. In each case, sonography was being performed to delineate the presence or absence of the spleen. The infant diagnosed by CT was studied on the first day of life. This infant died shortly thereafter. In each case, the left and right adrenal glands were seen to connect across the midline in a pre-aortic location. Each of the six neonates had asplenia syndrome and congenital heart disease. Five of the infants had no renal or spine anomalies, while the sixth had bilateral renal agenesis, multiple vertebral segmentation anomalies and sacral agenesis. This was the infant who died shortly after birth. Autopsy confirmed a pre-aortic horseshoe adrenal gland. The other five infants, all of whom survived the neonatal period, have not shown clinical or biochemical evidence for adrenal dysfunction.

\section{Discussion}

Congenital fusion of the two adrenal glands is a rare anomaly. In most reported cases the finding of a horseshoe adrenal gland was made at infant or fetal necropsy $[1,2,3,4,7,8,9,10,11,12,13,14,15,16,17$,
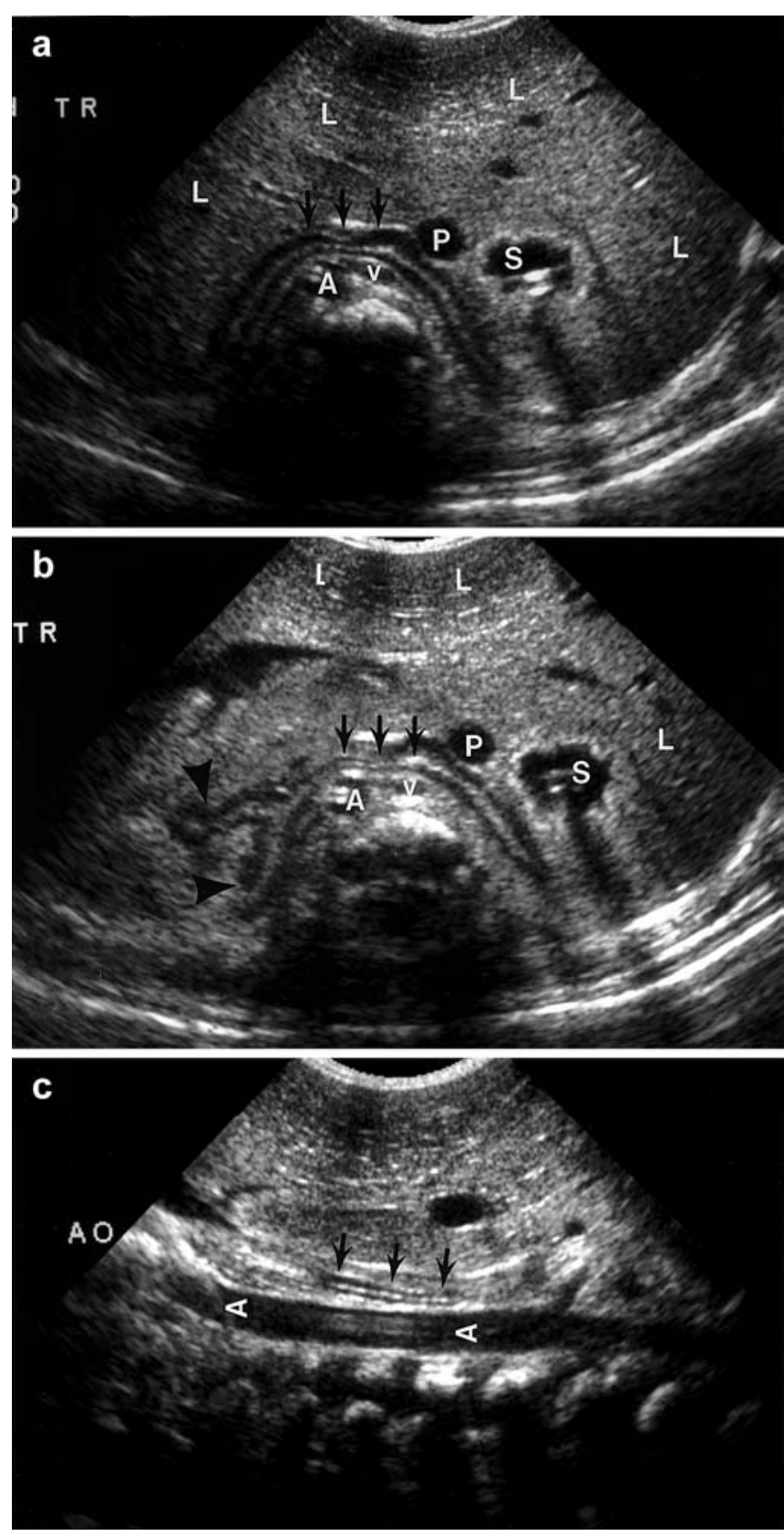

Fig. 1. A 1-day-old male infant with asplenia and horseshoe adrenal gland. a, b Transverse sonographic images of the upper abdomen show connection of the left and right adrenal glands across the midline (arrows) anterior to the right-sided aorta $(A)$ Hyperechoic central medulla and hypoechoic cortex are noted throughout the fused gland. Arrowheads identify two limbs of the right adrenal moiety. Similar anatomy was seen on the left (not illustrated) ( $v$ inferior vena cava, $L$ midline liver, $S$ stomach, $P$ common pulmonary vein). The patient had total anomalous pulmonary venous return draining to the portal vein. An umbilical arterial catheter is present in the aorta. c A longitudinal sonographic image shows the isthmus of the horseshoe adrenal gland (arrows) anterior to the aorta $(A)$ 
18]. There are three case reports of horseshoe adrenal glands identified by sonography in living infants $[5,6$, 19].

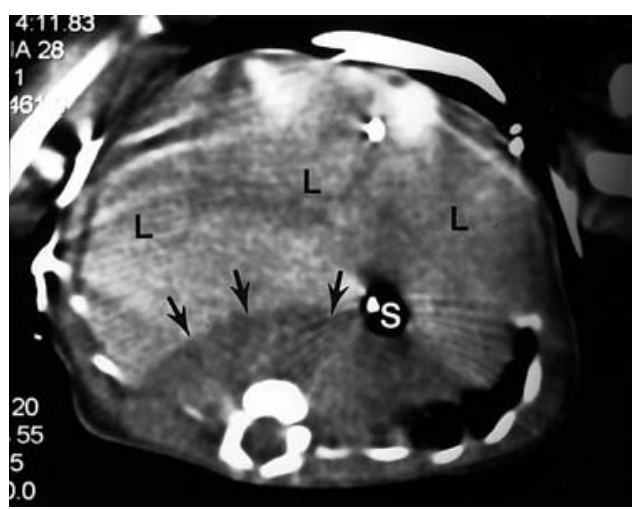

Fig. 2. A 1-day-old infant (chromosomes $46 \mathrm{XX}$ ) with asplenia, horseshoe adrenal gland, vertebral anomalies, sacral agenesis, bilateral renal agenesis, and ambiguous genitalia. An unenhanced CT image obtained shortly prior to death shows poorly defined, fused adrenal glands (arrows) (pathologically proven at autopsy). ( $L$ midline liver, $S$ stomach)
Anomalies of the adrenal glands are infrequently identified by imaging studies in living patients. Ipsilateral adrenal gland agenesis occurs in $10 \%$ of patients with unilateral renal agenesis and is believed to result from absence of the mesonephric ridge, rather than failure of the ureteric bud, as in the more typical isolated renal agenesis [20]. Congenital adrenal gland hypoplasia is associated with major central nervous system anomalies, such as anencephaly, and chromosomal defects, such as triploidy [7]. Small adrenal cortical rests are a common pathologic finding [12]. Adrenorenal and adrenohepatic fusion are uncommon [20]. Fusion of the adrenal gland with the kidney or the liver is thought to occur as a result of disruption of the intervening coelomic epithelium, allowing incorporation of the developing adrenal gland into the capsule of developing kidney or liver and thus fusion [20].

The embryologic origin of the horseshoe adrenal gland is unclear. The origin of the anomaly is likely in the early embryonic period, probably week $5-7$, based on the associated anomalies and evidence for normal histiogenesis and gland function [20]. It has been theo-

Table 1. Reported cases of horsehoe adrenal gland (Fetus diagnosis by fetal necropsy, US diagnosis by sonography, NS not specified, $M M C$ myelomeningocele, $C H D$ congenital heart disease (most, if not all, cases of asplenia included congenital heart disease)

\begin{tabular}{|c|c|c|c|c|}
\hline Case & Reference & Diagnosed by & $\begin{array}{l}\text { Pre-aortic vs } \\
\text { post-aortic }\end{array}$ & Major associations \\
\hline 1,2 & 1 & Autopsy & NS & Asplenia \\
\hline $3-6$ & 2 & Autopsy & NS & Asplenia \\
\hline $7-15^{\mathrm{a}}$ & 3 & NS & NS & Asplenia \\
\hline $16-24^{\mathrm{a}}$ & 4 & NS & NS & Asplenia \\
\hline 25 & 5 & US@1 day old & Pre & Asplenia \\
\hline 26 & 6 & US@ "newborn" & Pre & Asplenia \\
\hline 27 & 7 & Autopsy & NS & Asplenia \\
\hline 28 & 8 & Autopsy & NS & Asplenia \\
\hline 29 & 9 & Autospy & Pre & MMC \\
\hline 30 & 10 & Autopsy & NS & Cornelia-de Lange, hypoplastic kidneys, trilobed left lung \\
\hline 31 & 11 & Fetus & NS & MMC, bilateral renal agenesis \\
\hline 32 & 12 & Fetus & Post & Horseshoe kidney (anterior to aorta) \\
\hline 33 & 12 & $\mathrm{NS}^{\mathrm{b}}$ & Post & - \\
\hline $34-35$ & 13 & Fetus & NS & MMC \\
\hline 36 & 13 & Fetus & NS & MMC, bilateral renal agenesis, malrotation \\
\hline 37 & 13 & Fetus & NS & CHD, small spleen, bilateral renal agenesis, 2 foci ectopic adrenal cortex \\
\hline 38 & 13 & Fetus & NS & Craniorachischisis, malrotation \\
\hline 39 & 13 & Fetus & NS & Heterotaxy, bilateral trilobed lungs, CHD \\
\hline 40 & 14 & Fetus & Pre & MMC, bilateral renal agenesis \\
\hline 41 & 15 & Autopsy & Pre & Cornelia-de Lange, CHD, polycystic kidneys \\
\hline 42 & 16 & Autopsy & NS & MMC, bilateral renal agenesis, CHD, multilobulated spleen \\
\hline $43-54$ & 17 & Autopsy & Usually post & All MMC, $4 \mathrm{w} /$ unilateral renal agenesis, $3 \mathrm{w} /$ horseshoe kidney \\
\hline 55 & 18 & Fetus & NS & MMC \\
\hline 56 & 18 & Fetus & Post & Anencephaly, oomphalocele \\
\hline 57 & 18 & Fetus & Post & MMC, bilateral renal agenesis \\
\hline 58 & 18 & Fetus & NS & Anencephaly, oomphalocele, unilateral renal agenesis \\
\hline 59 & 19 & US@1 day old & Post & CHD, left pelvic kidney \\
\hline $60-64$ & Present & $\mathrm{US}^{\mathrm{c}}$ & Pre & Asplenia \\
\hline 65 & Present & CT@ first day of life & Pre & $\begin{array}{l}\text { Asplenia, bilateral renal agenesis, multiple vertebral anomalies, } \\
\text { sacral agenesis }\end{array}$ \\
\hline
\end{tabular}

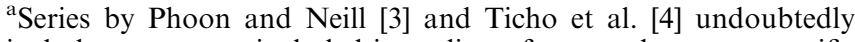
include some cases included in earlier references; however, specific case by case information is not available; most, if not all, cases from these two series are autopsy or fetal necropsy
${ }^{\mathrm{b}}$ The case by Potter was a pathologic diagnosis; however, it is not specified as to autopsy vs fetal necropsy

'Sonography at 1 day, 2 days, 3 days, 4 days, and 1 month of age 
rized that the anomaly is caused by disruption of intervening layers of coelomic epithelium, similar to adrenorenal and adrenohepatic fusion [13, 19]. Others have postulated that the adrenal gland may actually form from an anomalous single primordial gland rather than separate right and left glands [13]. This is supported by the association of fused adrenal glands with midline central nervous system defects and with failures of laterality (i.e., asplenia). Lastly, fetuses with severe neural tube defects may be disproportionately kyphotic [17]. It has been theorized that the resultant increased spacing of the spine, aorta, and developing abdominal organs allows for contact of the developing adrenal glands across the midline posterior to the aorta, and hence fusion [18].

We report six infants, each diagnosed with asplenia and with sonographic or computed tomographic demonstration of horseshoe adrenal gland. The table 1 summarizes our cases and the available information on 59 cases of horseshoe adrenal gland that were identified in the literature. Of the 65 cases, $34(52 \%)$ were seen in association with asplenia syndrome, $24(37 \%)$ with neural tube defects, 19 (29\%) with renal anomalies, and $2(3 \%)$ with Cornelia de Lange syndrome. In some cases, more than one of the aforementioned associations was noted. The neural tube defects varied in severity, with many being severe and prompting termination of pregnancy, or resulting in fetal demise or early neonatal death. The renal anomalies varied and included cases with both bilateral renal agenesis (6 cases) and horseshoe kidney (4 cases).

Asplenia, itself, is a form of heterotaxy syndrome denoted by bilateral right-sidedness. Asymmetric organs develop owing to the combination of rotation of dorsal and ventral precursors and/or the involution of one side of mirror-image structures. An exception is the spleen, which originates as a thickening in the left aspect of the dorsal mesogastrium [21]. Thus, in asplenia, bilateral right-sidedness, the spleen, a left-sided structure, is absent. Other characteristic, but variable features of asplenia include bilateral trilobed lungs, a horizontal midline liver, malrotation, and cardiovascular malformation $[1,2,3,4]$. Each of these facets of the syndrome represents a failure of an asymmetric organ to develop normally. Although the normal left and right adrenal glands differ slightly in shape, size, and location, suggesting subtle laterality, they are otherwise symmetric [22]. It is thus difficult to ascribe the horseshoe adrenal gland to a failure of laterality. However, one can also describe asplenia syndrome as a failure of structures of midline origin to develop normally [4]. As a result, failure of normal developing tissue planes or altered anatomy might allow for the left and right adrenal glands to contact across the midline and fuse. One could ascribe the difference in positioning of the fused adrenal gland in association with asplenia (always pre-aortic, when reported) and neural tube defects (often postaortic, when reported) to differences in position of primordial adrenal cortex cells in the coelomic epithelium relative to the embryonic aorta between the two groups $[6,8,9,12,14,15,17,18,19]$.

There have been no reported cases of horseshoe adrenal gland in association with polysplenia $[4,23]$. In one case of horseshoe adrenal gland described by Klatt et al. [13], complex anomalies included features of asplenia such as bilateral trilobed lungs with epiarterial bronchi, but the infant also had "situs inversus of the spleen and accessory spleen". Such cases, not strictly categorizable as either asplenia or polysplenia, serve to underscore the variability and overlap that may be present in infants with heterotaxy. In the series by Ticho et al. [4], horseshoe adrenal gland was seen in 9 of 91 cases with asplenia, but none of 58 with polysplenia. At the present, it would therefore appear that the finding of horseshoe adrenal gland may be a differentiating feature between asplenia and polysplenia. As the prevalence of horseshoe adrenal gland in asplenia is low $(\sim 10 \%$ in the series by Ticho et al. [4]), the absence of adrenal fusion does not exclude the diagnosis of asplenia.

In conclusion, horseshoe adrenal gland should be looked for in infants being studied for possible asplenia syndrome. Conversely, identification of a horseshoe adrenal gland should prompt a search for other features of heterotaxy. The anomaly may be more common than previously recognized. Although it appears that this anomaly may be an additional differentiating feature between asplenia and polysplenia, prospective study is needed.

\section{References}

1. Freedom RM (1972) The asplenia syndrome: a review of significant extracardiac structural abnormalities in 29 necropsied patients. J Pediatr 81:1130 1133
2. Rose V, Izukawa T, Moës CAF (1975) Syndromes of asplenia and polysplenia: a review of cardiac and non-cardiac malformations in 60 cases with special reference to diagnosis and prognosis. $\mathrm{Br}$ Heart J 37:840-852
3. Phoon CK, Neill CA (1994) Asplenia syndrome: insight into embroyology through an analysis of cardiac and extracardiac anomalies. Am J Cardiol 73:581-587 
4. Ticho BS, Goldstein AM, Van Praagh R (2000) Extracardiac anomalies in the heterotaxy syndromes with focus on anomalies of midline-associated structures. Am J Cardiol 85:729-734

5. Shafaie FF, Katz ME, Hannaway CD (1997) A horsehoe adrenal gland in an infant with asplenia. Pediatr Radiol 27:591-593

6. Horgan JG, Lock JH Jr, Cioffi-Ragan D (1995) Horseshoe adrenal in Ivemark (asplenia) syndrome J Ultrasound Med 14:785-786

7. Burke BA (1992) The pituitary, pineal, adrenal, thyroid, and parathyroid glands. In: Stocker JT, Dehner LP (eds) Pediatric pathology, Year Book Medical Publishers, Philadelphia, pp 9411001

8. Coen RW, Aase JM (1976) Fusion of the adrenal glands in association with asplenia [letter to the editor]. Pediatrics 88:152-153

9. Cameron AH (1957) Malformations of the neuro-spinal axis, urogenital tract and foregut in spina bifida attributable to disturbances of the blastopore. J Pathol Bacteriol 73:213-221
10. Huang C-C, Emanuel I, Huang S-W, et al. (1967) Two cases of the de Lange syndrome in Chinese infants. J Pediatr 71:251-254

11. Droste S, Fitzsimmons J, Pascoe-Mason J, et al (1990) Size of the fetal adrenal in bilateral renal agenesis. Obstet Gynecol 76:206-209

12. Potter EL (1952) Thymus and glands of internal secretion. In: Potter EL (ed) Pathology of the fetus and the newborn, 1st edn, The Year Book Publishers, Chicago, pp 269-288

13. Klatt EC, Pysher TJ, Pavlova Z (1998) Adrenal fusion. Pediatr Dev Pathol 1:475-479

14. Helmreich W (1944) Über eine Beobachtung von Nebennierenverschmelzung bei Spina Bifida und Aplasie der Nieren. Beitr Pathol Anat 109:511-520

15. Gans B, Thurston J. (1965) De Lange's Amsterdam dwarfs syndrome. Dev Med Child Neurol 7:42-45

16. Patel R-RA, Bixler D (1988) Renal agenesis with meningomyelocele and absence of Mullerian structures. Am J Med Genet 29:441-443

17. Gibson AAM (1974) Fused adrenal glands (abstract) Paediatric Pathology Society - Proceedings of the Eighteenth Annual Meeting. Arch Dis Child 49:75
18. Bell JE (1979) Fused suprarenal glands in association with central nervous system defects in the first half of foetal life. J Pathol 127:191-194

19. Burton EM, Strange ME, Edmonds DB (1993) Sonography of the circumrenal and horseshoe adrenal gland in the newborn. Pediatr Radiol 23:362-364

20. Skandalakis JE, Gray SW, Scaljon WM, et al (1994) The suprarenal glands. In: Skandalakis JE, Gray SW (eds) Embryology for surgeons, 2nd edn. Williams \& Wilkins, Baltimore, pp 718 735

21. Putschar WGJ, Manion WC (1956) Congenital absence of the spleen and associated anomalies. Am J Clin Pathol 26:429-470

22. Barr M Jr (2001) Organ asymmetries as correlates of other anomalies. Am J Med Genet (in press)

23. Peoples WM, Moller JH, Edwards JE (1983) Polysplenia: a review of 146 cases. Ped Cardiol 4:129-137 